\title{
guifi.net: A Bottom-Up Initiative for Building Free Telecommunication Infrastructure ${ }^{*}$
}

\author{
Miguel Pérez ${ }^{1}$, Pablo Boronat ${ }^{1}$, José A. Gil ${ }^{2}$, and Ana Pont ${ }^{2}$ \\ ${ }^{1}$ Universitat Jaume I, Castelló de la Plana, Spain \\ \{mperez,boronat\}@uji.es \\ ${ }^{2}$ Department of Computer Engineering \\ Universitat Politècnica de València, València, Spain \\ \{jagil, apont\}@disca.upv.es
}

\begin{abstract}
Building telecommunication network infrastructures is a key issue both, in developing regions and isolated areas in order to facilitate people not only access to information and new technologies, but also to give them the opportunity of self-organize. Nevertheless, despite the huge importance of the network infrastructure for the development of people, building a neutral and open communication system is not a priority for governments, so community networks are a solid and real alternative.

In this document we present guifi.net, a bottom-up community network, born in Spain, having over 30,000 active nodes, totaling more than 55,000 km in network links, and showing a sustained growing rate.

guifi.net is an opportunity to build a distributed telecommunications infrastructure governed by the participants in an indiscriminate way.

But a network such as guifi.net is not only of interest in developing areas. In many countries, internet connections, despite being a basic service, are usually monopolized by a small number of private companies. An open and free network as guifi.net offers users the opportunity of being participants in the decisions regarding infrastructure and services.
\end{abstract}

Keywords: telecommunication infrastructure $\cdot$ community networks $\cdot$ free access $\cdot$ digital gap

\section{Introduction}

Nobody doubts nowadays about the huge opportunities that Information and Communications Technologies (ICT) bring both the developed and developing world. Nevertheless many of these opportunities are completely lost in the case of developing countries or poor societies due to the lack of appropriate communications infrastructure. For instance, without this infrastructure the access to e-learning and e-health programs are not possible for many citizens; young people are losing many economic

* This work was partly supported by Spanish Ministry under Grant DPI2014-57746-C3 (MERBOTS Project). 
chances in the new digital society; and, in general, the most disadvantaged and unconnected socioeconomic groups are left behind and the digital divide is becoming wider.

Providing infrastructure communication for developing countries, rural areas or isolated communities should be a priority for governments. They should promote initiatives in this sense, motivating telecommunication companies to invest in developing infrastructure to facilitate every individual the use of ICT. But the ugly truth is the opposite. Building the infrastructure is not currently a key issue in practice. Even more, powerful telecommunications companies don't see a good business in providing infrastructure for many geographic areas (areas with low population density or underdeveloped) and then, they simply ignore the problem.

To deal with this lack of official interest the community initiative is making progress in many countries and, literally speaking gaining ground progressively. In this paper we present guifi.net [1, 2], a bottom-up community initiative, developed initially in Catalonia and extended currently to the rest of Spain, aimed at providing free connectivity to everyone no matter where they live and their economic status. guifi.net is also the history of David vs Goliath but in this work we just focus on presenting how it works and how it is expanding and covering a large part of our country. We also point some ideas to export the experience to other countries, especially those with poor or inexistent communications infrastructure with the aim of bridging the technological gap.

\section{Motivation}

Just over a decade, when WiFi wireless devices started to become popular [3], many bottom-up community networks were created by citizens [4, 5], usually enthusiastic of technology and communications. The participation and management in these networks are usually open to any individual, firm, company or public administration.

guifi.net [1] was another of these community networks that appeared at first in the county of Osona in Catalonia, where the councils of Vic and Gurb are located. In fact, the name of the network is a combination of Gurb and WiFi.

At the beginning there are usually two main non-exclusive reasons that can encourage individuals to create their own community network: i) there are some people, activist and enthusiast of new technologies, that want to be independent of big telecommunication companies and, ii) there are other people who suffer what is known as the digital divide (either for lack of telecommunications infrastructure supply, either for economic reasons).

Unlike other eminently urban communities, guifi.net was born in a rural area with little economic interest for private operators, as they had to make a investment to deploy infrastructure in a geographical area with low density of potential customers. That was the reason why a group of people began to organize themselves to build their own network infrastructure. Today, almost all wireless communities that were created years ago in Spain have disappeared or have joined guifi.net. In fact, guifi.net 
has grown and has become, as far as we know, the largest active community network in the world [6].

But why guifi.net had sustained growth and other networks were not? This is because since its beginning, the enthusiastic people of Osona, and especially Ramon Roca who lead the project, had the vision to prepare and organize the network growth. Everything was conceived taking into account that more people would and could be connected in a future and thus they will contribute expanding the network.

However, this is more complicated than it seems at first sight, because a high number of issues must be considered such as, a technical organization that allows steady growth with limited human intervention; the implementation of a website where all the necessary information is centralized (locations, links, network addresses, emails of the participants, maps, monitoring tools, etc.); the dissemination of the initiative, its operation and its organization through workshops and talks; the review of legal issues that may affect the network; holding meetings with politicians, administrations and companies to offer new perspectives and alternatives, etc. All these questions are not simple and they require a huge effort and an almost perfect organization.

Fig. 1 shows guifi.net web homepage. This website provides information about the project, contains a guide for connecting new nodes, and also provides technical support, offers user's chats, etc.

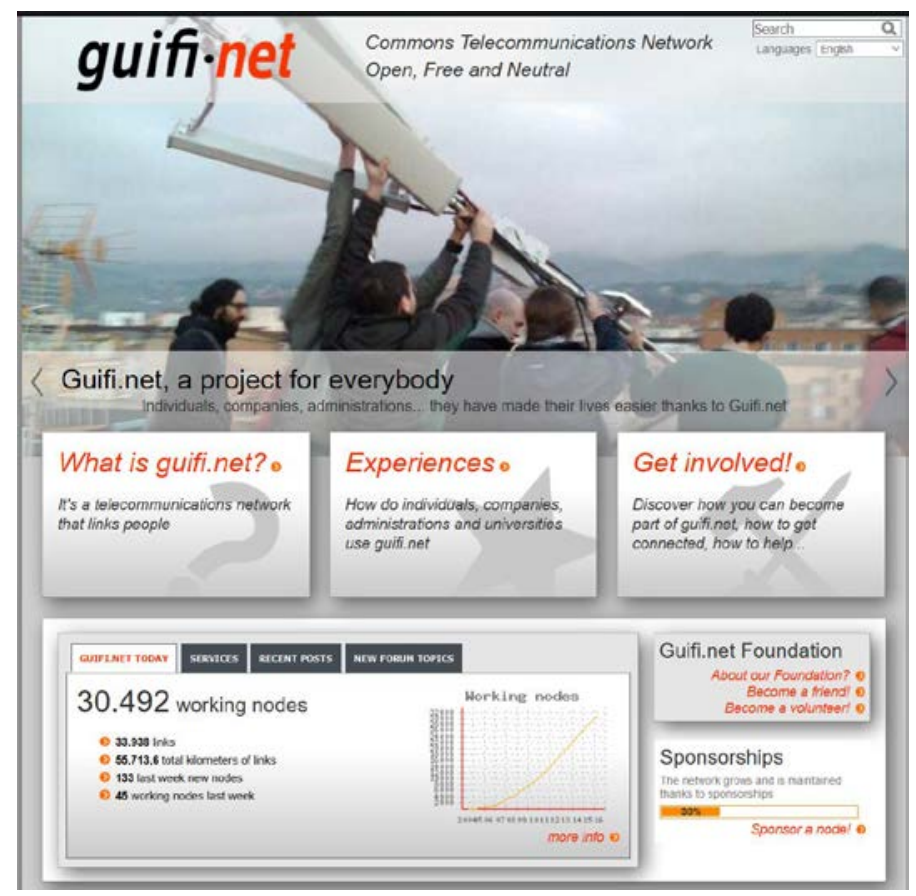

Fig. 1. The guifi.net website homepage.

Initiatives like guifi.net can also help to limit the use or waste of public money, which generally tends to flow towards a few hands. We could also limit the pressure of eco- 
nomic powers that control basic services for people. In short, community networks can permit a more distributed, participatory, transparent and democratic management of any basic service. After all, what is most feared by regimes with no freedom? Two things: people having access to information and their ability to organize.

But beware; all those nice words imply high costs, hard and continuous work, patience and to be bound to the understanding and cooperation.

\section{$3 \quad$ What guifi.net is?}

It is said that guifi.net is a free, open and neutral network. This means that the network as a whole, does not belong to anyone (no predominance), everyone can connect (obviously saving technical problems) and it is independent of the content or services (simply an infrastructure that people use as they want). Next the main aspects that define what guifi.net is are explained.

\subsection{Network funding.}

The network grows when someone adds new infrastructure, but this infrastructure has a cost. In the case of customers or end nodes they had to assume the associated cost, in a similar way that happens when you install a single television antenna. In the case of optical fiber deployment or installation of supernodes (nodes that allow connection to client nodes and participate in the routing task), there is a common infrastructure to be afford. For funding this infrastructure several methods can be used.

One of the funding methods, that makes it quickly growing is that the network is partially supported by the active involvement of many municipalities and some universities and schools that have installed guifi.net nodes to facilitate citizens and students the access to the services that they offer. These facilities, are usually carried out using public funds, and are also available for any private operator who wants to drive traffic and sell services on the free network.

Another form of funding is sponsorships. It is a kind of patronage or crowdfunding among users. When someone proposes a new location, a budget is proposed to install a node that provides new coverage or improves the network. People who are interested in the facility agree to cooperate economically. To this end, a web application has been developed to show the contribution commitments and the amount of funds available. Once, the donations cover the cost, the node installation is performed.

There are other types of financing. For example, people interested in a specific facility can advance the money for it to be done quickly, and later, if someone wants to participate in the network using that facility must pay a fraction of the cost, usually without trading margin and becoming co-owners of the facility proportionally to the payment done.

Finally and specially in the case of optical fiber infrastructure, the installation and maintenance costs can be distributed equally among private operators who do business on these services. In any case, the aim is to spread the costs of infrastructure facilities including those who can take advantage of them. 


\subsection{Network technology.}

Worth mentioning that guifi.net, despite its name, it is not tied to any particular technology. The most appropriate technology for each case can be used. Currently, most of the network is based on WiFi technology in infrastructure mode (in which the nodes can be access point or client nodes), but there are areas that operate in mesh or ad hoc mode (where nodes act simultaneously as access point and client at the same time), or other areas where the infrastructure consists in fiber optic links. This latest technology is requiring a huge organizational challenge, both for economic management as for the deployment problems.

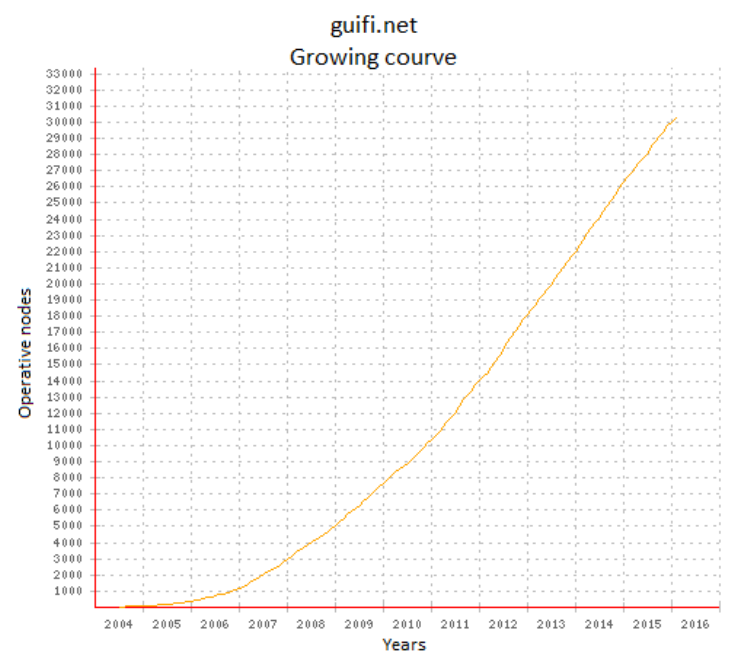

Fig. 2. guifi.net growth curve.

guifi.net is an open transport network, and users can deploy any kind of service in it (like Internet access, Web servers, VoIP, p2p file sharing, etc.). Among new users, there is often confusion between guifi.net connection and access to Internet. Although guifi.net is connected to the Internet as an operator (in the Internet Exchange Point of Barcelona), guifi.net does not offer direct internet access. This connection is used to allow the access from the Internet to the services of guifi.net and is marketed by private operators that base their business on this network. From the point of view of guifi.net, Internet access is another service on the network, which must be provided by the participants.

But the truth is that guifi.net facilitates this basic Internet access service in different ways. For example, private operators can offer it cheaper because they do not have to deploy or rent their own network. Many municipalities, usually small villages, offer free web browsing (via a web proxy) through guifi.net (as an example, only in the province of Castelló more than 50 villages offer this facility). Companies or neighboring communities can share the same access to the Internet thanks to the free 
network that facilitates their access. Also, a subscriber to an ADSL line at home can share it with other community members or use it from a second home.

The fact of having a self-managed network and at cost (no profit margins for the use of the network itself) can offer many other applications to individuals and companies, as for example: to manipulate remote automatic systems or to control systems or domotic installations.

\subsection{Network organization.}

The network expands when individuals, companies or entities connect to the network, and therefore, opening new regions. These new regions will be capable of carrying traffic from other points or nodes.

There are many interests that may collide with each other in the use of the network, occasionally disagreements or conflicts may arise. To resolve them and to ensure the basic principles of the network, when creating nodes or network regions, a license called Interconnection Agreement or XOLN (Xarxa Oberta, Lliure i Neutral which means: Open, Free and Neutral Network) must be accepted. With this agreement legal and ethical aspects are addressed; such as that network connection must not be discriminatory, what kind of traffic manipulation is allowed and which is not, what are the network legal responsibilities, or how potential conflicts will be resolved. The XOLN is inspired by free software licenses, but adapted to communications systems.

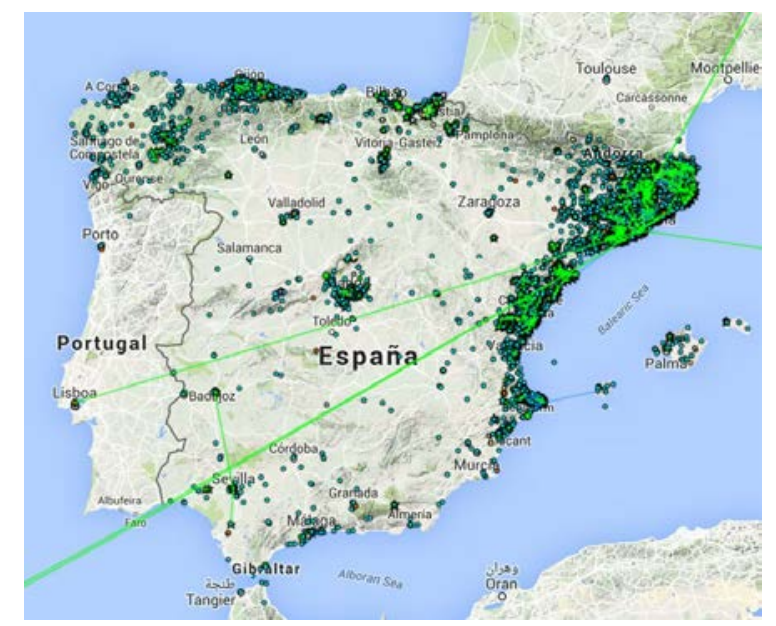

Fig. 3. guifi.net deployment in the Iberian Peninsula (January 2016)

For conflict management, legal defense or representation of the network against others, a non-profit organization, guifi.net Foundation [7] has been created. For example, to amend the interconnection agreement, which is quite unusual; proposals are addressed to the Foundation. The Foundation filters them and proposes a reasoned writing, then amendments are discussed until a consensus and finally, if necessary, changes are incorporated in the XOLN. 
To give an idea of the size of the network today, there are about 30,000 active nodes totaling a 55,000 km linear network. Fig. 2 shows the expansion of the network since its beginning in 2004, while Fig. 3 shows the deployment of the network in the Iberian Peninsula.

\section{$4 \quad$ How does it work?}

In guifi.net most of the network acts as a wireless WiFi network in infrastructure mode. Fig. 4 illustrates the topology of this kind of infrastructure.

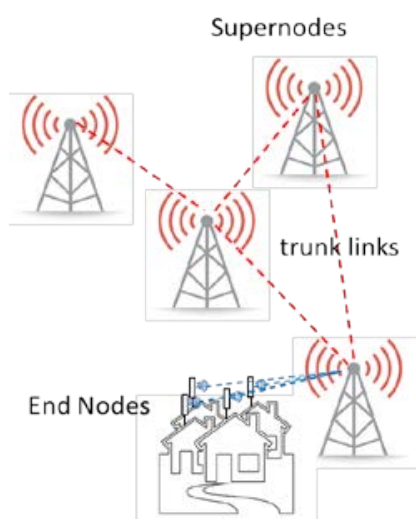

Fig. 4. guifi.net topology.

Let's see how this type of infrastructure network is organized. A node is a guifi.net installation (even if it is an island) located in a geographical place that can be found on the map of guifi.net. In infrastructure mode, there are two types of nodes:

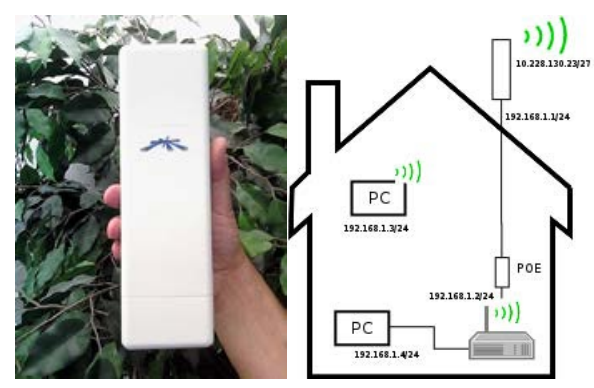

Fig. 5. Example of a customer or end node.

- Customer or end nodes. These nodes are not suitable for connecting new nodes. They only provide network connectivity to end users. For example, a single family house or a neighborhood community can share a client node. This means that these nodes can have multiple users (or connected devices). Usually the node has two In- 
ternet Protocol addresses (IP). A public IP in the range 10.0.0.0/8, assigned automatically by the web application (currently we use IPv4 addresses) and, another private IP in the range 192.168.0.0/16. Private addresses are for single users, in a similar way that IP addresses are organized to perform an ADSL connection through an ISP. Privates IP are only for domestic or internal networks and are not part of guifi.net or managed by guifi.net. The infrastructure cost of these end nodes may currently be around $100 €$. Fig. 5 shows a photo of an integrated outdoor antenna-radio-router and a schematic example of the structure of an end node in a family house.

- Multiradio nodes or supernodes. These nodes usually have more than one radio or antenna. The photo of Fig. 6 shows the supernode at the roof of the School of Informatics in the Universitat Politècnica de València. Some radios are used for connecting client nodes and other radios for point-to-point links that interconnect supernodes (backbone links). Nodes also have almost one router involved in dynamic routing (usually through OSPF or BGP protocols [8]). The cost of these nodes is normally shared between users and the price of the hardware infrastructure may be around $600 €$. It must be considered that labor cost for the installation of this type of nodes often surpasses the cost of the material.

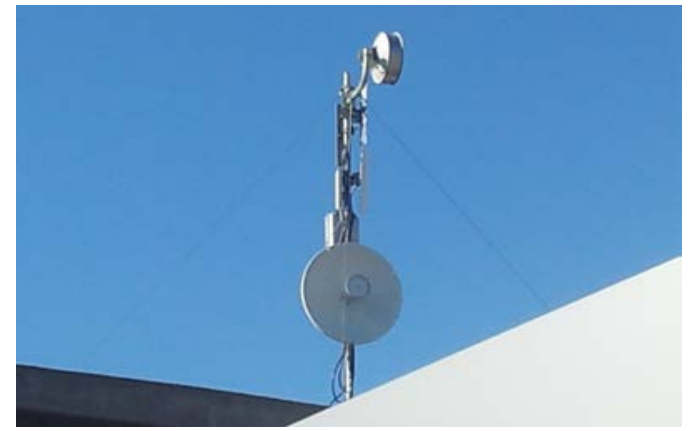

Fig. 6. Supernode at the Universitat Politècnica de València

guifi.net public IP's are coordinated directly from the website (http://guifi.net). For an antenna that provides coverage to customers usually it has up to 29 IP addresses (one network mask of 27 bits within the range 10.0.0.0/8). For point-to-point links, the web application assigns addresses in the range 172.16.0.0/12; these are networks that use two IP address (netmask of 30 bits).

Nodes are administered through the website. When a new node is registered its location should be included on the map. Each node has its own homepage providing all type of information about the node and permitting to contact the owner via email. This enables users to organize themselves to expand or upgrade the network.

In addition to the website, the support for users also includes different email lists organized by geographical areas and topics, a social network, forums and instant messaging channels. All these media can be found in the Support section of the website and are used by network users to contact each other and coordinate operations on the network. 


\section{$5 \quad$ How to join guifi.net community}

Being part of the guifi.net network is not a complicated process, but minimal technical knowledge is required. As mentioned above, the vast majority of the network is operated in infrastructure mode. In this section we discuss how to join the network using this mode and assuming that there is already a nearby network infrastructure (the antennas currently used in guifi.net for client nodes are able to cover distances of $5 \mathrm{~km}$ or more provided there is line of sight path).

Basically, the requirement is to connect a WiFi antenna (usually in the U-NII $5 \mathrm{GHz}$ band) with one of the supernodes that form the backbone of guifi.net. The router of the new node must have an IP in the range used by the supernode. guifi.net website is responsible for coordinating and distributing the IPs between nodes.

For connecting a new node three basic steps are needed. These three steps are described in detail in the website (http://guifi.net/es/threesteps):

1. Adding a new node on the guifi.net website. This is to locate on the map the geographical position in which the new node will be physically located.

2. Adding a router (with radio and WiFi antenna) to the node. In this step the model of the router to be installed is required. This information has to be uploaded in the corresponding entry that was created in the previous step associated to the new node.

3. Defining the link. That is, what supernode and which of their radios is to be bound to the new node. In this step is when the web application assigns the IP address for the new node.

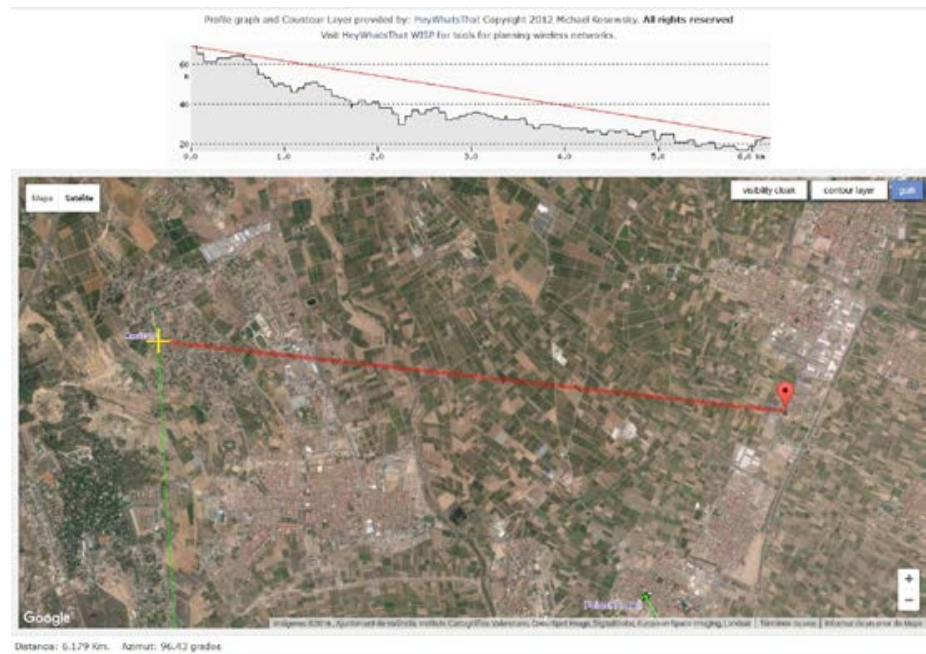

Fig. 7. Example of tools to plan new links.

After performing these three steps, the web application is then able to generate the configuration file for the router, including the Extended Service Set Identifier (ESSI), IP, gateway, and other technical parameters needed (at least for those devices com- 
monly used in guifi.net). This process is known as "unsolclic" (meaning "just one click" which give us an idea about how easy the process is). After loading this configuration file on the router, it will be ready to connect to the supernode and access any service offered in guifi.net.

Before starting the three steps process, some details have to be taken into account. To add the node in the website (step 1), previously a user account should be created. As Fig. 7 shows, there are several tools that can help us to plan and define the new links. But, although in the guifi.net map the link we want to create can appear as feasible, we should ensure that there are still available IP addresses and that the signal strength is adequate. For the latter we must go up to the roof with the antenna to detect all possible WiFi signals (the ESSID's belonging to our radios begin with guifi.net- followed by a location summary). However, if the process is too complicated, an installation technician can be called. There are professionals spread across all areas covered by guifi.net and they can be located by searching the guifi.net website.

\section{How to collaborate in the guifi.net project?}

The best way to collaborate is extending the network by creating your own node, even if in your geographical area there are still no nodes. In the case of a new area it is important to contact with the city council, neighborhood association or cooperatives. If an initial installation is done and a service is provided, such as a web proxy, the word of mouth marketing will facilitate the expansion. In http://social.guifi.net there are always volunteers to help and answer questions.

There are also other ways of collaboration in the project. The guifi.net Foundation combines the efforts of several working groups that can provide support with technical issues, as well as legal aspects, promotion and dissemination of the network.

Although we have discussed the general interests of guifi.net in previous sections, we also want to emphasize its international vocation. The larger the network, the more transparent, the more equitable and the more sustainable it will be.

In fact, multinationals do their own thing and it would be of high interest to know if an open and joint infrastructure project like guifi.net could also operate as a new type of multinational.

Like in the free software movement where software can be used globally, the guifi.net platform, its management model and the lessons learned could be also used in many different countries instead of wasting energy by reinventing the wheel. In any case, contributions and improvements are always welcome.

To introduce the community network in other continents, countries and regions (which is already being done) is an activity that can also allow us to test new technologies. For example, in Spain, networks with ad hoc routing protocols in wireless networks have not grown too much, in part because the infrastructure operating mode is well known and there are trained installers.

The internationalization of guifi.net could mean some legal problems due to the existence of different legislations, but it should not be a major obstacle (except in 
countries with restricted freedom) considering the permeability of standards and markets.

One of the features that, in our opinion, should have a community like guifi.net is the capability to exercise surveillance over investments made with public money; both on investments in proprietary networks, closed to the general public, and on the money allocated for the promotion of private networks under the pretext of improving the market. Among the functions that guifi.net should play are, on one hand, to facilitate the organization of small operators who can take part in major projects, and on the other hand, being critical of granting investments of doubtful viability or excessive amounts.

Among others awards and prizes [4], the guifi.net project got the "European Broadband Awards 2015" awarded by the European Community for its model of economic management which is an honor and a pride for all its members.

\section{Other community networks}

As discussed in section 1, after an initial boom in which appeared a high number of initiatives aimed at creating community networks, there are some few good examples of networks that survived their first years and look healthy in different parts of the world. These networks extend their infrastructure by connecting sections that are managed in a distributed manner. In IPv4 there was a global framework for the coordination of private address ranges so that if different networks are connected, there are not duplicate addresses. This organization was called freenetworks.org. Unfortunately it seems that this organization currently has no activity.

Other networks with the same philosophy as guifi.net can be found, among many others, in countries like Austria (Funkfeuer [9]), Germany (Freifunk 10), Greece (AWMN [11]) and USA (Keratoconus [12]).

Usually there is a common misunderstanding between free or community networks and other networks that facilitate sharing Internet access as FON [13]. Community networks extend network infrastructure; on this infrastructure services can be provided or not. Instead of this, FON [14] is a company that enables people to share their Internet access (free or not) but no network infrastructure is created by the community. FON is rather a federation of domestic access points. Community networks stress on working on the extension of a network infrastructure in order to enable a certain degree of independence of telecommunications companies and its business model based on a proprietary and closed network. On this infrastructure community networks can grow other services such as guifi.net web proxies.

\section{Conclusions}

In this paper we have presented guifi.net, a bottom-up community network for building free access telecommunication infrastructure.

guifi.net is an actual alternative for providing open access to the Information and Communication Technologies to everybody, regardless of socioeconomic status, geo- 
graphical region of residence or country of birth, thus contributing to bridge the digital gap.

In our work we explain what guifi.net is, the main reasons that motivated its creation more than 10 years ago, how it works and how it is becoming a social phenomenon in Spain.

We have also provided information for joining the network and collaborating with the project, and finally, we hope that our work can contribute to spread guifi.net around the world and encourage more people to join it, thus expanding its area of action and promoting digital inclusion.

\section{Acknowledgments}

We would like to express our deepest gratitude to Ramon Roca for leading the guifi.net project. Without his valuable initiative, hard work, and dedication, this network would never have been possible. We would also like to thank all the members of this community, many of them completely anonymous, because they have made possible the growth and expansion of the network.

\section{References}

1. Wikipedia. guifi,net, https://es.wikipedia.org/wiki/guifi.net

2. guifi.net Red de Telecomunicaciones del Procomún Abierta, Libre y Neutral. https://guifi.net/es

3. Gast, Matthew S.: 802.11 Wireless Networks: The Definitive Guide, Second Edition, O’Reilly Media Inc. 2013 (tenth release)

4. Schuler, Douglas: New Community Networks., Addison-Wesley, 1996

5. London, Scott: Civic Networks: Building Community on the Net. In Composing Knowledge, edited by Rolf Norgaard (Bedford/St. Martin's, 2007)

6. J. Jiménez et al., "Supporting cloud deployment in the Guifi.net community network," Global Information Infrastructure Symposium - GIIS 2013, Trento, 2013, pp. 1-3.

7. Fundació guifi.net. http://fundacio.guifi.net

8. Black Uyless N. IP Routing Protocols - RIP, OSPF, BGP, PNNI \& Cisco routing protocols. Ed. Prentice Hall, 2000

9. Funkfeuer. http://www.funkfeuer.at

10. Freifunk. https://freifunk.net/en/

11. Athens Wireless Metropolitan Network (AWMN) http://www.awmn.net

12. The Global Keratoconus Freedom Group http://www.kcfreedom.net

13. Wikipedia. FON. https://es.wikipedia.org/wiki/FON

14. FON. Global Wifi Network. https://corp.fon.com 